\title{
Incômodos nas salas de aula: Cenas para pensar discursos de heterossexualidade
}

\author{
Disturbances in the classrooms: Scenarios to think discourses of \\ heterosexuality
}

Luciana Borre Nunes ${ }^{i}$

\section{Resumo}

Este texto apresenta um recorte de pesquisa sendo desenvolvida no Programa de PósGraduação em Arte e Cultura Visual da Universidade Federal de Goiás. Os dados foram produzidos em uma escola da rede pública de Goiânia, Goiás, com estudantes do $3^{\circ}$ ano do Ensino Fundamental. O texto discute diferentes narrativas escolares que, de alguma maneira, constituem-se como mecanismos disciplinadores e produtores de gênero e sexualidade. Tem como foco a constituição de masculinidades através de artefatos culturais presentes na escola, buscando entender como os discursos heteronormativos da instituição influenciam os relacionamentos sociais. A perspectiva pós-estruturalista associada a princípios da cultura visual sustenta os referenciais teóricos da pesquisa.

Palavras-chave: Cultura Visual, Masculinidades, Sala de Aula, Heteronormatividade.

\begin{abstract}
The text presents part of an investigation being developed in the Graduate Program in Art and Visual Culture at the Federal University of Goiás. Data was produced in a public school in Goiânia, Goiás, with $3^{\text {rd }}$ graders from Elementary School. This paper discusses different school narratives that somehow are constituted as disciplining mechanisms and producers of gender and sexuality. It focuses the constitution of masculinities through cultural artifacts at school, trying to understand how the institution heteronormative discourses influence social relations. The poststructuralist perspective associated to visual culture principles grounds the theoretical framework of this investigation.
\end{abstract}

Keywords: Visual Culture, Masculinities, Classroom, Heteronormativity.

O que perturba é a falta de incômodo. Situações conflitantes e vivências instigantes sobre questões de gênero e sexualidade acontecem na escola sem provocar desconforto na maioria das/os educadoras/es. É possível que a rotina escolar obscureça nossos olhares, ou, ainda é possível que não nos sintamos atingidos ou incomodados pelas experiências pessoais trazidas pelas/os estudantes para as salas de aula. Existe, também, a possibilidade de estarmos profundamente imersos em uma área de estudo ou na defesa de um ideal de sujeito escolarizado. Talvez, essa condição, nos impeça de ver ou, nos ajude a não querer ver certos assuntos e questões que circundam e circulam no ambiente escolar.

A ausência de incômodo em relação aos discursos que normatizam gênero e sexualidade na escola é uma das questões que orienta a investigação de doutorado no Programa de Pós-Graduação em Arte e Cultura Visual da Universidade Federal de Goiás. A discussão 
sobre sexualidades heteronormatizadas é parte do estudo que desenvolvo sobre a constituição de masculinidades nas salas de aula através da mediação com artefatos culturais.

Acompanhei duas turmas do 30 ano do Ensino Fundamental de uma escola da rede Estadual de Ensino de Goiânia durante 2011. Algumas questões me acompanharam nesse percurso: como masculinidades são constituídas através de artefatos culturais em sala de aula? Como meninos entre 8 e 11 anos de idade constituem suas masculinidades através de elementos visuais específicos do seu cotidiano? Como meninos do $3^{\circ}$ ano do Ensino Fundamental manifestam suas representações de masculinidade no âmbito escolar? Como são produzidas as "tramas" pedagógicas para a constituição de gêneros e sexualidades?

Neste artigo, narro cenas de sala de aula que passaram a incomodar. Causaram dúvidas, questionamentos e impacto sobre minha posição como educadora e pesquisadora. $O$ que problematizo é a falta de incômodos das/os professoras/es em relação a questões de gênero e sexualidade na escola e a maneira como discursos de heterossexualidade são naturalizados sem que haja debate e reflexão.

O processo investigativo gerou episódios que instigam questionamentos sobre discursos que naturalizam a heterossexualidade $\mathrm{e}$ as práticas de relacionamentos amorosos. A primeira cena de sala de aula apresenta a preferência das/os estudantes pela telenovela "Rebelde", artefato cultural que faz pedagogia ao ensinar como adolescentes "ficam" e namoram, ocultando qualquer tipo de sexualidade não heterossexual em sua trama. A segunda cena mostra uma conversa com as crianças sobre uma foto tirada por um menino durante a realização de um projeto pedagógico. Essa cena expõe imagens religiosas de Jesus e Maria. Baseados no discurso religioso as crianças defendem que heteronormatividade é o padrão ideal e, portanto, o esperado, em detrimento dos supostos desvios gerados pela homossexualidade. Ficou evidente a repulsa de imagens que não apresentem ou atendam expectativas construídas a partir de concepções heterossexuais. Estas situações geraram reflexões sobre as atribuições da escola como espaço para discussão e problematização de discursos naturalizados. 


\section{Narrativas e normativas heterossexuais na escola}

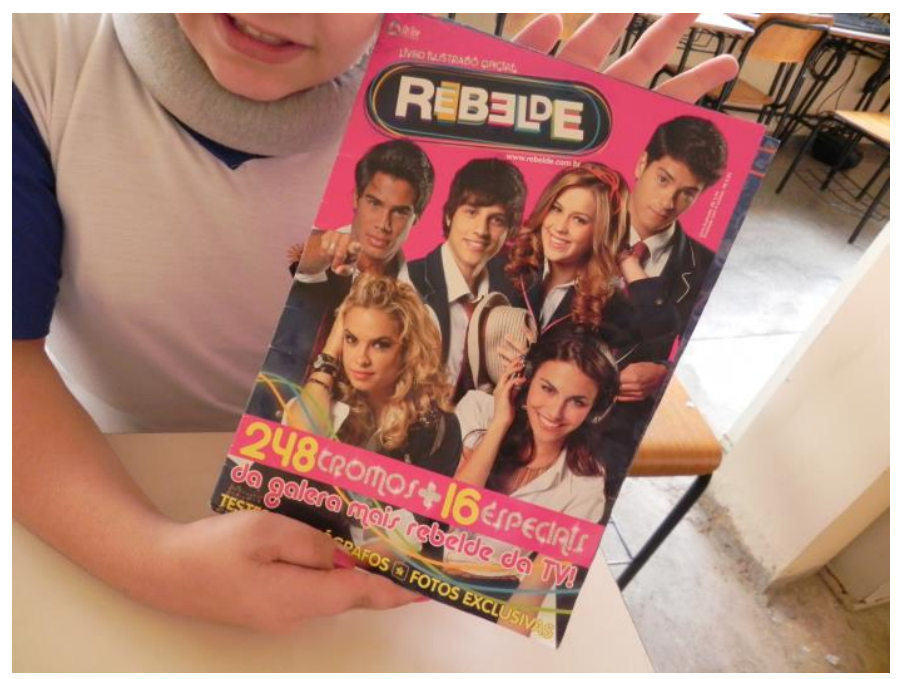

Figura 01 - Imagem da autora produzida durante a pesquisa de campo na escola (2011)

Ketlen, Thamara, Carlos, Weder, Luis e eu assistimos o episódio da telenovela "Rebelde" no qual dois personagens, Pedro e Alice, "ficam" escondidos e quase são flagrados pelo inspetor da escola. Eufóricos, as/os estudantes iniciaram a discussão:

Tia, não perca hoje que vai tá pegando fogo! O Binho vai lutar pela Roberta e a Roberta não vai querer ele. (Thamara, 8 anos)

Eu namoro escondido, namoro lá na sala na hora do recreio. Chego lá e Óhhh!... (Luis, 9 anos)

Tem uns que ficam na porta só olhando... Quem faz isso é viado e gayzinho.

(Weder, 10 anos)

\section{Perguntei:}

E lá nos Rebeldes? Tem isso?

Em coro, os cinco estudantes repulsaram minha pergunta.

Eu ia achar a novela muito ruim. Eu ia ver um monte de homem beijando na boca de homem e eu ia achar ruim. (Carlos, 9 anos)

Não tem nenhum gay, graças a Deus! Ainda bem! E eles iam chegar no diretor e iam falar porque nenhum deles ia gostar do gayzinho. (Weder, 10 anos)

A minha mãe também vê a novela porque ela gosta. Aí se ela vê um gay se beijando ela diz: "Luis, você não pode assistir isso, eu não quero meu filho virando um gay". (Luis, 9 anos)

Interferi mais uma vez:

_ Por que não tem problema ver um casal como a Roberta e o Diego se beijando? 
Não, né! Porque é um homem e uma mulher. Homem beija homem e mulher beija mulher... Eu não gosto! É nojo e eu não gosto. (Carlos, 9 anos)

E se isso acontecesse nos Rebeldes eu ia detestar. Aí eu não ia ser rebelde. (Thamara, 8 anos)

Eu não ia assistir Rebelde nunca. (Weder, 10 anos)

Em sala de aula percebi que o grupo adolescente Rebeldes estava na preferência da maioria dos estudantes das turmas. Minha surpresa, no entanto, foi constatar que alunas e alunos não estavam somente adquirindo os produtos relacionados ao grupo, mas, estavam aderindo, sem qualquer tipo de questionamento ou problematização, às maneiras de pensar e agir produzidas pelas narrativas desses artefatos culturais.

Os personagens estavam presentes de maneira significativa no cotidiano das/os estudantes que, em diversos momentos, utilizavam vocabulário próprio do programa, cantavam e solicitavam atividades diferenciadas relacionadas a essa preferência. Meu olhar pedagógico foi envolvido pelas preferências das turmas que demonstravam grande entusiasmo ao falar sobre o grupo "Rebelde", suas músicas, seus comportamentos, práticas e episódios. Procurei acompanhar alguns capítulos da telenovela para me aproximar ou me familiarizar um pouco com essas narrativas, tentar compreender o porquê desse modo de pensar e agir tão impactante e, sobretudo, buscar manter um diálogo produtivo com as crianças. Ficou evidente, que as/os estudantes estavam reproduzindo em sala de aula comportamentos e ensinamentos assistidos no programa. Visualizei em minha prática investigativa aquilo que Martins e Tourinho destacam como as "... culturas da mídia, com seus personagens, imagens, significados, jargões e, principalmente, com um modo próprio de expressar ideias e pensamentos, [que] constrói mundos e histórias de mundos que invadem o imaginário infantil" (2010, p. 42). Essa invasão no imaginário infantil repercutiu nas atitudes das crianças que passaram a ser "Rebeldes".

Durante as observações percebi e registrei que os Rebeldes iniciaram sua entrada na sala de aula de maneira sutil e sem confrontar as normas disciplinares da escola. Entre elas a proibição do uso de celulares, de aparelhos eletrônicos e de qualquer tipo de material que perturbasse a concentração nas aulas e o rendimento nas avaliações, tais como bolas, rádios, álbuns de figurinhas, maquiagens e brinquedos. O início da invasão Rebelde nas turmas 3B e $3 \mathrm{~A}$ foi pacífica, através de músicas cantadas pelas alunas e alunos durante o recreio ou quando a professora se ausentava da sala por alguns instantes. 
Depois, apareceram os materiais escolares decorados com os Rebeldes e roupas que começaram a substituir os uniformes. Também surgiram os primeiros desenhos produzidos entre uma atividade escolar e outra. As letras das músicas começaram a ser conhecidas e cantadas por mais estudantes. Os nomes dos personagens foram assumidos como identidade das alunas e alunos. Julia, por exemplo, deixou de ser chamada pelo seu nome e a ser reconhecida como Roberta, personagem loira, uma das protagonistas na novela.

Entendi que os Rebeldes estavam exercendo pedagogias nas salas de aula. Estavam sugerindo comportamentos e influenciando o modo como meninas e meninos devem agir, falar, pensar e se comportar. A trama da telenovela mostrava como devem ser as atitudes em um relacionamento amoroso heterossexual, ocultando, negligenciando e ridicularizando a homossexualidade. Como discursos heteronormativos constituem uma das principais fontes de aprendizagem sobre gênero e sexualidade na escola? Como as/os estudantes aprendem sobre ser feminino e masculino na relação do "ficar" e/ou namorar? Que idealizações de relacionamentos amorosos são construídas pela trama? E a escola, quais são as suas atribuições diante das experiências visuais das/os estudantes com os Rebeldes?

Pinho é um dos personagens que as crianças consideram ser gay por apresentar trejeitos femininos e temer insetos. O personagem tem pequena participação na trama e é considerado o "gordinho amigo de todos". É simpático, alegre, engraçado, faz todos rirem com suas atitudes desastradas e está sempre ajudando os demais. Suas características evocam a imagem estereotipada do "gordinho alegre e amigo" e sua possível identidade homossexual é ocultada. As crianças não se sentem seguras para afirmar que ele é gay, dúvida que não existe em relação aos outros personagens protagonistas.

A homossexualidade aparece na trama, mas é estrategicamente ocultada e mascarada pelas atitudes cômicas de Pinho. Abordar diferenças de identidades sexuais parece ser tarefa complexa e conturbada. Percebo a constante tentativa de ocultar o assunto ou qualquer situação que perturbe o ambiente normativo heterossexual pelo qual transitamos. Como consequência, a matriz hegemônica heterossexual reforça a condição em que "todos os sujeitos e comportamentos que não se 'enquadrem' dentro dessa lógica ou não são percebidos ou são tratados como problemas e desvios" (Louro, 2007a, p.77) 
Assim como outros artefatos culturais, os Rebeldes estão ensinando como ser menina e menino. Estão sugerindo, definindo comportamentos para cada gênero e instaurando maneiras de olhar determinadas situações sociais. Por isso, considero importante pensar sobre como os Rebeldes estão fazendo gênero, construindo sexualidades e como a escola pensa e/ou trabalha com essas questões.

Os Rebeldes invadiram as salas de aula de maneira efetiva e muitas foram as situações nas quais eles demarcaram presença. Enquanto eu estava sentada no fundo da sala para ajudar um aluno na sua atividade de português, escutei a professora iniciar uma explicação sobre classificação morfológica das palavras. Um menino começou a cantar uma música dos Rebeldes em voz baixa. Em seguida, uma menina recitou a letra da música "jeito Rebelde de ser" que estava entre as folhas do caderno e, do outro lado da sala, dois meninos trocaram bilhetes sobre a programação e os próximos episódios da telenovela. A turma estava silenciosa. Mesmo sem a atenção e interesse das/os estudantes, a professora demonstrou satisfação com suas explicações.

Pensar sobre a constituição de gênero e sexualidade através dos Rebeldes também possibilita problematizar sobre aquilo que a escola considera importante de ser trabalhado. Rebeldes não fazem parte do conteúdo curricular do $3^{\circ}$ ano e nem estavam presente nos planos das professoras. Os Rebeldes não participaram do currículo oficial, mas estavam nas salas de aulas através dos gestos e preferências dos estudantes. Estavam presentes na escola, constituindo e influenciando pensamentos e ações que não foram discutidos pelas/os educadoras/es. Duncun (2011, p. 22) defende práticas pedagógicas baseadas na problematização das interpretações dos artefatos culturais ao dizer que "o currículo deveria, pois, basear-se na natureza da cultura visual, especificamente nas experiências dos alunos relativas a ela $e$ integradas ao conhecimento do professor."

As experiências culturais trazidas pelas/os estudantes para as salas de aula são fonte de importantes reflexões sobre assuntos naturalizados e tratados como normas de conduta. No entanto, experienciei o repúdio das/os educadoras/es aos artefatos culturais oriundos da mídia televisiva e o silenciamento das questões que trazem para as salas de aula. Questões de gênero e sexualidade estão presentes no cotidiano escolar, mas são desconsiderados por um currículo que privilegia aspectos formais e tradicionais de ensino. Louro (2007a, p. 81) afirma que "não há dúvidas de que o que está sendo proposto, objetiva e explicitamente, pela instituição escolar é constituição de sujeitos masculinos e femininos heterossexuais." 
$\mathrm{Na}$ narrativa televisiva, os Rebeldes instauram situações heteronormativas que são valorizadas e reproduzidas pelos estudantes em sala de aula. Durante os encontros do grupo focal, em vários momentos, surgiram falas que corroboram com o discurso heterossexual adolescente reafirmando o interesse dos alunos pelos "encontros escondidos" entre os dois personagens protagonistas. Na maioria dos episódios, as músicas cantadas contam histórias de paixões, relacionamentos e envolvimento entre casais heterossexuais.

As alunas e alunos relataram com propriedade diversas situações nas quais estão em jogo os relacionamentos amorosos entre os personagens da trama. "Ficar" e namorar são temas correntes na novela. Os estudantes conhecem detalhes e demonstram que estão atentos, ligados a esses jogos amorosos. Eles transportam os fatos dos episódios da novela para as relações interpessoais em sala de aula. Durante um dos encontros uma menina me procurou para contar que a Roberta e o Diego da novela estavam "ficando". Percebi seu ar de felicidade ao fazer o relato e perguntei qual o motivo de tanta alegria. Ela revelou que, por ser a Roberta, sonhava com a possibilidade de 'ficar' com o Diego, o seu colega Carlos.

Em outro momento perguntei para os estudantes se os relacionamentos que aconteciam na novela também estavam acontecendo entre eles. As meninas ficaram desconcertadas e, sorriram ao mesmo tempo em que os meninos repudiaram a ideia afirmando que isso era somente ficção, a vida real era muito diferente.

Relacionamentos amorosos são produzidos pelos Rebeldes através das histórias dos personagens, influenciando e sugerindo condições sobre como "ficar" e/ou namorar. A ausência de outras referências favorece apenas um modo de ver e entender a sexualidade deixando outras possibilidades à margem do que poderia ser considerado normal. Assim, além de regular as sexualidades através de um enredo heteronormativo, os Rebeldes também direcionam ou instituem maneiras de se relacionar amorosamente. São as práticas comuns e naturalizadas que atuam como eficientes normatizadores comportamentais.

A naturalização de determinados discursos são práticas políticas. Práticas inseridas em relações de poder que estão em constante negociação. Os Rebeldes, assim como outros âmbitos e narrativas, legitimam a heterossexualidade afirmando e mostrando que isso é natural. Ao ser naturalizado, tudo que não se enquadra nesse parâmetro passa a ser repudiado. Quando perguntei para as crianças sobre as possibilidades de outros tipos de relacionamentos amorosos obtive como resposta a repulsa e até mesmo indignação com 
o meu comentário. As/os estudantes evidenciam a heterossexualidade como valor do seu cotidiano e diversos são os encaminhamentos para acreditarem que a heterossexualidade é o único caminho a ser seguido. As crianças participantes da pesquisa (poderia denominá-los pré-adolescentes) "ficam", beijam na boca ou estão se encaminhando para isso, tem seus dramas pessoais por gostarem das/os colegas, mas ainda brincam de bater um no outro na tentativa de chamar a atenção. Luis (9 anos) afirmou que "aqui todo mundo beija". O menino estava se referindo a beijar somente meninas e esta é uma das aprendizagens no contexto escolar.

Os meninos da turma aprenderam que, em algum momento, deverão beijar uma menina e que a possibilidade de uma ação ou comportamento divergente desse padrão significa ser estigmatizado por apelidos pejorativos. Aprendem que gostar de meninas é a ordem natural de suas escolhas e que qualquer outra possibilidade não pode e não deve ser pensada. Carlos (9 anos) afirmou que "tem uns que ficam na porta só olhando... [assistindo o colega beijar uma menina] Quem não faz isso é viado e gayzinho", revelando que aqueles que não se enquadram nessa perspectiva são considerados "anormais", fora dos padrões aceitáveis.

Esses meninos aprendem e são ensinados a gostar somente de meninas, rejeitando outras possibilidades de relacionamento. Ser "gayzinho" é um desvio, uma ofensa, algo a ser combatido e que não encontra espaço na escola e na trama dos Rebeldes. Os ídolos dessas crianças são notoriamente heterossexuais e os dramas de seus personagens estão geralmente relacionados a namoros, "ficar" e sexo. Essa configuração está consolidada como modelo e como prática ideal e, em decorrência, as/os estudantes não admitem ou imaginam algum tipo de relação que divirja ou se diferencie desse padrão.

Ao manifestar meu estranhamento por ver somente personagens que namoravam e ficavam somente com parceiros do sexo oposto, as crianças combateram veementemente qualquer possibilidade de relação divergente do padrão heteronormativo na trama. Reagiram como se eu estivesse falando ou propondo algo inimaginável para o mundo dos Rebeldes. Depois da minha "estranha" pergunta, passaram a pensar no assunto. Demonstraram aversão e, posteriormente, tranquilidade ao confirmarem que não há personagens gays na telenovela. Carlos ( 9 anos) mostrou alívio ao dizer "como na [telenovela] Rebelde... Não tem nenhum gay, graças a Deus! Ainda bem!"

Os Rebeldes não seriam os mesmos se insinuações ou comportamentos homossexuais fizessem parte da trama. Para as crianças, não causa estranhamento ver Roberta e Diego se beijando todos os dias ou, ainda, acompanhar Pedro e Alice encenando situações que 
fazem alusão à primeira relação sexual do casal. Naturalizados, essas cenas e episódios se estabelecem como normas atender, definem parâmetros e apontam a opção correta, "segura". Segundo Carlos (9 anos) a telenovela não seria a mesma se houvesse outras possibilidades: "eu ia achar a novela muito ruim. Eu ia ver um monte de homem beijando na boca de homem e eu ia achar ruim". Thamara (8 anos) ressaltou: "aí eu ia detestar. Aí eu não ia ser rebelde".

Rebelde é um dos muitos artefatos culturais presentes no cotidiano dessas crianças. Existem outros que naturalizam o discurso normativo da heterossexualidade, entre eles as narrativas religiosas apresentadas no relato de outra situação escolar com os mesmos estudantes. Na segunda cena de sala de aula a discussão começa a partir de uma foto religiosa de Jesus e Maria mostrada por um dos meninos. Weder (10 anos), referindo-se à imagem, afirmou que Jesus Cristo deu algumas regras para ser homem.

\section{"Jesus não fez ele pra ser gay"}

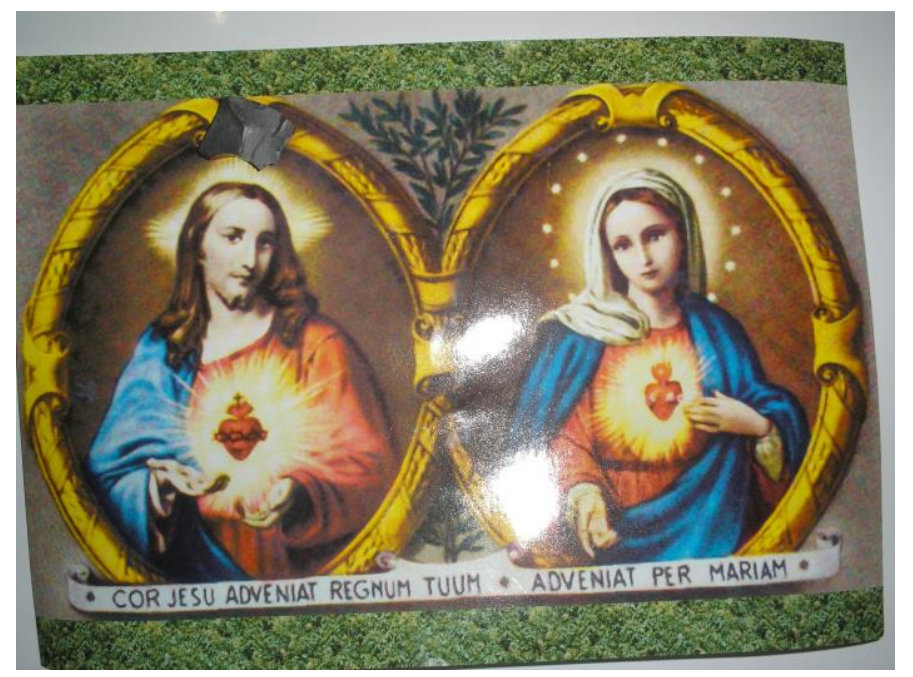

Figura 02 - Foto tirada por um dos alunos durante a pesquisa de campo (2011)

Existem regras para ser menino? Quais? Imersa e provocada por essas questões, lancei-as aos estudantes e fui surpreendida com:

Não namorar com homem, com gay. (Weder, 10 anos)

E também não vir de saia ou calcinha. (Luis, 9 anos)

_Quando os meninos do $4^{\circ}$ ano tão desconfiando que a gente tá de calcinha, eles vem e abaixam a nossa calça. Pegam nossa calça e descem. Só pra ver se a gente tá de calcinha. (Carlos, 9 anos)

O menino da outra turma era gay. Ele saiu da escola. (Luis, 9 anos) 
_ Tia, o Samuel é gay, mas nem parece porque ele é muito forte. Um dia um menino veio me bater e ele disse pra não bater.

Perguntei:

Existe problema em ser gay?

É viado. O Jesus não fez ele pra ser gay, fez pra ser homem. O Jesus fez. Ele

tá confuso. (Luis, 9 anos)

Não fez pra namorar com homem. Fez a gente para namorar com mulher.

Foi Deus. (Weder, 10 anos)

Pedi para explicarem o significado de "estar confuso":

_ O Jesus fez ele homem e não mulher e ele tem que ficar com mulher, mas ele gosta de homem. (Luis, 9 anos)

_É horrível! Porque ele gosta de homem e não pode. (Frederico, 9 anos)

Por que essas crianças acreditam que "ficar", beijar e namorar são atribuições somente de casais heterossexuais? Por que beijo entre homens ou mulheres é algo maléfico e influenciaria negativamente?

A trama Rebelde, assim como os discursos religiosos apresentados nesse relato, instituem maneiras de pensar e agir. Definem como os relacionamentos amorosos devem acontecer e afirmam a heterossexualidade como o padrão a ser seguido. Martins e Tourinho (2011, p. 54) explicam que "ao naturalizar certas idéias e valores, nossa história/trajetória cultural vai configurando, gradativamente, nosso modo de ver o mundo, ou seja, predispondo-nos a vê-lo de determinadas maneiras." Nesse sentido, posso afirmar que o processo de desnaturalização deve ser tratado como uma das atribuições das instituições escolares.

As práticas pedagógicas da escola onde realizei a pesquisa de campo são exemplo do modo como discursos religiosos são consolidados como valores inquestionáveis. Todos os dias, crianças e educadoras/es rezam a oração do "Pai Nosso" e fazem preces antes de iniciar o turno de aula. Momentos de silêncio, concentração e disciplinamento dos corpos enquanto meninas e meninos são mantidos em fila. Os conteúdos do ensino religioso preveem trabalho com histórias, parábolas e outros ensinamentos de Jesus Cristo.

Ao mesmo tempo e, de maneira contraditória, o discurso sobre a importância do respeito às diferenças é frequente na escola. No entanto, como pensar ou ser diferente em um contexto que privilegia somente uma maneira de olhar e abordar a questão? Como as/os estudantes podem questionar discursos religiosos hegemônicos se aprendem que esses 
são únicos e corretos? Como ser ou pensar diferente se não há espaço para discutir e refletir sobre discursos normativos?

O discurso sobre a necessidade de respeito às diferenças está na ordem do dia e está presente no âmbito escolar. Está nos planos de aula, nos planejamentos anuais, nos objetivos dos projetos e nas falas das/os educadoras/es. Para Louro (2007a, p. 44), é necessário aprofundarmos essa questão, pois "nos discursos atuais, o apelo à diferença está se tornando quase um lugar comum (o que já nos leva a sermos cautelosas/os, desconfiando de seu uso irrestrito)". Importa saber quem define a diferença, quem é considerado diferente e o que significa ser diferente. Nesse jogo de poder negociam-se desigualdades. Nesse contexto onde predominam padrões unificados de comportamentos, o discurso do respeito às diferenças esmaece, se desgasta a ponto de tornar-se leviano. Respeitar as diferenças não implica somente aceitar o outro, o que ele tem ou o modo como pensa, mas, legitimá-lo e compreender suas "versões de realidade".

A perspectiva pós-estruturalista põe em cheque dicotomias que envolvem identidades de gênero e sexualidade, problematizando a polarização entre homem/mulher, homossexual/ heterossexual. Louro (2007a, p. 30) afirma que "é preciso desconstruir o caráter permanente da oposição binária masculino-feminino". No jogo das dicotomias os pólos se diferem e adquirem características próprias, negando o outro extremo e mantendo-se distantes. Esse tipo de pensamento dicotômico demarca os relacionamentos e nos aprisiona em um pólo, fazendo-nos renegar e excluir o que é oposto. A desconstrução dessas polaridades é tarefa difícil porque não aprendemos a transitar entre as polaridades e, principalmente, porque procuramos nos enquadrar naquilo que um dos extremos exige e oferece. Essa dificuldade de permanecer em trânsito, cambiante e disposto a mudar de posição na linha da dicotomia é tarefa das discussões pós-estruturalistas sobre gênero.

Louro (2007a, p. 48) explica que "a concepção fortemente polarizada dos gêneros esconde a pluralidade existente em cada um dos pólos. Assim, aqueles homens que se afastam da forma de masculinidade hegemônica são considerados diferentes, são representados como o outro e, usualmente, experimentam práticas de discriminação ou subordinação."

A lógica binária nos leva a consolidar posições e fixar lugares. Não se admite o desvio de rotas. Não se pensa no transitar sem a fixação em um determinado ponto. Desconstruir 
significa entender como essas polaridades se formaram e romper o que está naturalizado.

Relações dicotômicas estabelecem dominantes e dominados. A heterossexualidade se mantém como uma das extremidades que se constitui em oposição à homossexualidade, considerada como desviante. Discutir as polaridades é reconhecer que há caminhos que entrecruzam as relações de identidades sexuais e de gênero. Por que representações homoafetivas são censuradas pelas crianças e consideradas como algo que influencia negativamente sua sexualidade? Por que não há questionamento sobre representações de gênero e sexualidade na escola? Por que educadoras/es geralmente temem e silenciam essas questões?

A heteronormatividade é um modelo/padrão definido socialmente. Quando não atendido, iniciam-se os problemas e angústias para aqueles que apresentam sexualidade não normativa. Qualquer prática fora da normalidade encontra dificuldade de ajuste e de pertencimento, pois é exigida uma conduta alinhada e naturalizada entre gênero, sexo e sexualidade. Louro (2007a, p. 67) argumenta que talvez seja mais importante escutar o que não é dito em sala de aula e dar atenção ao que está ocultado:

Provavelmente nada é mais exemplar disso do que o ocultamento ou a negação dos/as homossexuais - e da homossexualidade pela escola. Ao não falar a respeito deles e delas, talvez se pretenda 'eliminá-los $/ s^{\prime}$, ou, pelo menos, se pretenda evitar que os alunos e as alunas 'normais' os/as conheçam e possam desejálos/as. Aqui o silenciamento - a ausência da fala - aparece como uma espécie de garantia da 'norma'. A ignorância (chamada, por alguns, de inocência) é vista como mantenedora dos valores ou dos comportamentos 'bons' e confiáveis. A negação dos/as homossexuais no espaço legitimado da sala de aula acaba por confiná-los às gozações e aos insultos dos recreios e dos jogos, fazendo com que, deste modo, jovens gays e lésbicas só possam se reconhecer como desviantes, indesejados e ridículos.

A heterossexualidade é uma prática social incorporada como legítima. A telenovela Rebelde, os discursos religiosos e as práticas escolares de silenciamento são mecanismos que propagam, confortam e mantém uma única possibilidade de abordar e viver a sexualidade. É resultado da preocupação e da vigilância dos corpos por meio de práticas que restringem a todos dentro da escola. Crianças, professoras/es e demais participantes da comunidade escolar são impelidos a atender essas normatizações sobre suas identidades de gênero e sexualidade. Abreu (2010, p. 200) amplia a discussão ao fazer o seguinte comentário: 
A heterossexualidade segue sendo o padrão que impõe a conduta ideal das identidades sexuais e, como não podia ser diferente, a família, os processos de ensino, os discursos institucionais e as práticas do cotidiano são os pilares que conduzem, ditam e normatizam os papéis e as regras sexuais. No entanto, contraditoriamente, a homossexualidade, a bissexualidade, os interssexuais, os travestis, o transformista, a androgenia e a ambivalência, são sujeitos cada vez mais visíveis, mas, ainda, marginalizados nos lugares onde circulam, mediam e estabelecem suas relações.

Sendo a heteronormatividade a regra geral, aqueles que não se adéquam à regra acabam sendo isolados e repudiados. Abreu (2010, p. 201) destaca que "o repúdio ao que é diferente gera muitos problemas às pessoas fora da heteronormatividade uma vez que tem que crescer, desenvolver-se e construir-se em um mundo com poucas características de identificação, o que torna a auto-aceitação de sua sexualidade algo ainda mais difícil."

A omissão ou silêncio dos educadoras/es em relação às discussões sobre gênero e sexualidade não significa que esses assuntos não estejam presentes na escola. Ao contrário, o ocultamento e o silenciamento são por si só a produção de gênero e sexualidade a partir de uma matriz heterossexual. Louro (2007a, p. 81) afirma que "a sexualidade está na escola porque ela faz parte dos sujeitos, ela não é algo que possa ser desligado ou algo do qual alguém possa se 'despir"'. A tarefa de desnaturalização dos discursos normativos ainda é problemática nas escolas.

\section{Porque a ausência de incômodo perturba!}

As cenas narradas aconteceram e foram registradas em 2011, durante processo de investigação com as/os estudantes do $3^{\circ}$ ano do ensino fundamental de uma escola da rede pública de ensino em Goiânia. No entanto, situações semelhantes as que foram narradas são vivenciadas todos os dias no ambiente escolar. São interações presentes no cotidiano das salas de aula, mas que, por várias razões, não provocam as/os educadoras/es a pensarem, discutirem ou analisarem a possibilidade de abordar tais temáticas. Constatei que esses assuntos não incomodam as/os educadores. O incômodo acontece quando artefatos culturais como os Rebeldes, entram na sala de aula para "atrapalhar" o desenvolvimento das disciplinas e a aplicação dos conteúdos previstos.

Temas ligados à sexualidade estão presentes no cotidiano escolar, mas, geralmente, de maneira camuflada e quase sempre, ocultada ou sufocada pelos conteúdos estabelecidos nos planos de estudo. Apesar de estar presente nas conversas e no dia a dia das/os estudantes, sexualidade é tema que fica "escondido", encoberto e disfarçado. É abordado 
ou debatido em circunstâncias especiais, de modo geral, quando acontece algum problema, algum caso específico que desafia e afronta a inércia do corpo docente.

As crianças falam, discutem e vivenciam assuntos relacionados à constituição de gênero e sexualidade em muitos momentos no cotidiano da escola. Mas, o que me instiga e motiva a realizar esta pesquisa, é a necessidade de compreender por que, mesmo estando presentes, esses assuntos não merecem a atenção e, sobretudo a reflexão da comunidade escolar. Essa acomodação ou, dizendo de outra maneira, essa ausência de incômodo, perturba e, de certa forma, frustra o que considero uma oportunidade para uma formação crítico-reflexiva de educadores e estudantes.

\section{Referênci}

as

ABREU, Carla Luzia. Um olhar sobre construções de identidade de gênero na contemporaneidade. Revista Visualidades, volume 8, FAV/UFG: 2010, p. 191-204.

DUNCUM, Paul. Por que a arte-educação precisa mudar e o que podemos fazer. MARTINS, Raimundo; TOURINHO, Irene (Orgs). Educação da cultura visual: conceitos e contextos. Santa Maria: Editora UFSM, 2011, p. 15-30.

LOURO, Guacira Lopes. O currículo e as diferenças sexuais e de gênero. In: COSTA, Marisa Vorraber (Org.). O currículo nos limiares do contemporâneo. Rio de Janeiro: DP\&A, 2005, p. 85-92.

LOURO, Guacira Lopes. Gênero Sexualidade e Educação: Uma perspectiva pósestruturalista. Rio de Janeiro: Petrópolis, 2007a.

- Currículo, gênero e sexualidade. In: LOURO, Guacira Lopes; FELIPE, Jane; GOELLNER, Silvana Vilodre (Orgs.). Corpo, gênero e sexualidade: um debate contemporâneo na educação. Petrópolis (RJ): Vozes, 2007b, p. 42-52.

MARTINS, Raimundo; TOURINHO, Irene. Culturas da infância e da imagem: aconteceu um fato grave, um incidente global. In: MARTINS, Raimundo; TOURINHO, Irene (Orgs.). Cultura visual e infância: quando as imagens invadem a escola. Santa Maria: Editora UFSM, 2010, p. 37-45.

MARTINS, Raimundo; TOURINHO, Irene. Circunstâncias e ingerências da cultura visual. In: MARTINS, Raimundo; TOURINHO, Irene (Orgs.). Educação da cultura visual: conceitos e contextos. Santa Maria: Editora UFSM, 2011, p. 51-68. 
' Doutoranda do Programa de Pós Graduação em Arte e Cultura Visual, Universidade Federal de Goiás. Iucianaborre@yahoo.com.br

Recebido em: 23/09/2013

Aprovado em: 15/10/2013 